\title{
THE PREPARATION OF SOFT MAGNETIC COMPOSITES BASED ON FeSi AND FERRITE FIBERS
}

\author{
M. Strečková, M. Fáberová, R. Bureš, P. Kurek
}

\begin{abstract}
The fields of soft magnetic composites and powder metallurgy technologies have a powerful potential to redesign the way of electric motor preparation, and will continue to grow for years to come. A design of the novel soft microcomposite material composed of spherical FeSi particles and $\mathrm{Ni}_{0.3} \mathrm{Zn}_{0.7} \mathrm{Fe}_{2} \mathrm{O}_{4}$ ferrite nanofibers is reported together with a characterization of basic mechanical and electrical properties. The needle-less electrospinning method was used for a preparation of $\mathrm{Ni}_{0.3} \mathrm{Zn}_{0.7} \mathrm{Fe}_{2} \mathrm{O}_{4}$ ferrite nanofibers, which has a spinel-type crystal structure as verified by XRD and TEM analysis. The dielectric coating was prepared by mixing of nanofibers with glycerol and ethanol because of safe manipulation with fumed fibers and homogeneous distribution of the coating around the FeSi particle surface. The final microcomposite samples were prepared by a combination of the traditional PM compaction technique supplemented with a conventional sintering process of the prepared green compacts. The composition and distribution of the secondary phase formed by the spinel ferrite fibers were examined by SEM. It is demonstrated that the prepared composite material has a tight arrangement without any significant porosity, which manifest itself through superior mechanical properties (high mechanical hardness, Young modulus, and transverse rupture strength) and specific electric resistivity compared to the related composite materials including resin as the organic binder.
\end{abstract}

Kewords: composite, $\mathrm{FeSi}$ powder, $\mathrm{Ni}_{0.3} \mathrm{Zn}_{0.7} \mathrm{Fe}_{2} \mathrm{O}_{4}$ ferrite nanofibers, needle-less electrospinning process, PM technologies

\section{INTRODUCTION}

Future soft magnetic composites (SMCs) allow sophisticated and revolutionized designs, minimization or maximization electromagnetic devices with improved efficiency and reduced weight and cost, without sacrificing magnetic performance. Generally, SMCs require low core losses, which is secured by highest electrical resistivity and high magnetic permeability at various frequency ranges for diverse applications such as aerospace and automobiles [1]. Moreover the functional SMCs require materials with superb soft magnetic properties and posses the high handling strength in a manufacturing facility and perform at high speed. Therefore a selection of materials for preparation of SMCs lies in balancing high electrical resistivity, high mechanical strength, and high magnetic performance utilizing both a core and coating material, or maybe a new class of materials [2].

\footnotetext{
Magdaléna Strečková, Mária Fáberová, Radovan Bureš, Pavel Kurek: Institute of Materials Research, Slovak Academy of Sciences, Watsonova 47, 04001 Košice, SR
} 
A core material that allows for the highest magnetic permeability, obtained by high densities, low coercivity, and high magnetic induction, coupled with a coating material that allows for the lowest core losses, obtained by high electrical resistivity and good magnetic capabilities will be the ideal solution for SMC applications. It is well known that the core/shell particles can be processed by Powder Metallurgy (PM) methods. PM technologies are indeed able to produce SMCs with a high enough density and sufficiently stable mechanical properties, whereas an insulating layer between magnetic powder particles ensures a high electric resistivity that minimizes the overall magnetic losses [3]. A lot of efforts have been devoted to a preparation of SMCs composed of different ferromagnetic base materials (Fe, FeSi, Permalloy, Vitroperm, etc.) and different hybride organic resins (mostly of phenol-formaldehyde type) used as an insulating coating [4,5]. However, it is worthwhile to remark that a thermal treatment of these materials is strictly limited by a thermal resistance of the insulating organic material, which is inadequate in order to remove plastic deformations created during a preparation of green compacts [6]. In this regard, another promising way in order to produce SMCs with excellent properties consists in using spinel ferrites as a coating with an extremely high electric resistivity and almost zero eddy current losses in alternating magnetic fields, which will not basically affect the magnetic characteristics of metal cores (high magnetic flux density, low coercitive force) [7]. One-dimensional nanostructured ferrites have received considerable attention due to their attractive high-tech applications. Spinel ferrites have their efficient absorptions with the working frequency of electromagnetic wave limited approximately up to $1 \mathrm{GHz}$, though the bandwidth of absorption is wide $[8,9,10]$. Among spinel ferrites, nickel ferrite $\mathrm{NiFe}_{2} \mathrm{O}_{4}$ has attracted a considerable attention due to their high magnetocrystalline anisotropy, coercivity, magnetostrictive coefficient, chemical stability and mechanical hardness [11]. It shows that short fibers with a high aspect ratio can bring a much higher magnetic permeability than the same volume of materials in non-fibrous form [12]. Nanofibers can be produced form a wide range of polymers. These fibers have extremely high specific surface area due to their small diameters, and nanofibers mats can be highly porous with excellent pore interconnection. Electrospinning is currently the most promising technique to procure continuous nanofibers with diameters adjusted form nanometers to micron. $[13,14]$. The most of researchers pay their attention to the study of the fibers formation from a liquid polymer jet reservoir in a longitudinal electric field. However, the limitation of the mass yield from an electrospinning process using the jet often does not comply requirement for today industrial-level production. Therefore, the free liquid surface technology was used in the present work as economically viable to produce fibers in a mass of industrial scale [15].

In the present work the fine ferrite $\mathrm{Ni}_{0.3} \mathrm{Zn}_{0.7} \mathrm{Fe}_{2} \mathrm{O}_{4}$ nanofibers were produced by the needle-less electrospinning method as a one of the most suitable, cost-effective and versatile techniques for fibers preparation on a large scale. TG/DSC analysis of $\mathrm{PVA} / \mathrm{Ni}$, $\mathrm{Zn}, \mathrm{Fe}$ nitrate precursor fibers was performed in order to set the final calcination temperature for $\mathrm{Ni}_{0.3} \mathrm{Zn}_{0.7} \mathrm{Fe}_{2} \mathrm{O}_{4}$ fibers. XRD, SEM and TEM analysis for verification of spinel structure and ferrites morphology was used. The ferrite fibers were mixed with glycerol or ethanol for safe and high-quality coating preparation due to their high powdery nature. The glycerol was used due to its high viscosity and low temperature of pyrolysis with the small percentage of residuals content. Finally, the PM technologies such as uniaxial compaction and conventional sintering process were applied for final samples production. 


\section{EXPERIMENTAL}

\section{Fibers preparation}

The precursor solution for the electrospinning were prepared by mixing of $7 \% \mathrm{wt}$. water solution of polyvinyl alcohol (PVA, Acros Organic, Mw = 146,000-186,000 g/mol) with appropriate amount of metal nitrates (Acros Organic, $\mathrm{Ni}\left(\mathrm{NO}_{3}\right)_{2} \cdot 6 \mathrm{H}_{2} \mathrm{O}$, $\left.\mathrm{Zn}\left(\mathrm{NO}_{3}\right)_{2} \cdot 6 \mathrm{H}_{2} \mathrm{O}, \mathrm{Fe}\left(\mathrm{NO}_{3}\right)_{3} \cdot 9 \mathrm{H}_{2} \mathrm{O}\right)$. The molar ratio of $\mathrm{Ni}^{2+} / \mathrm{Zn}^{2+} / \mathrm{Fe}^{3+}$ ions was set to $0.3 / 0.7 / 2$ in order to maintain the molar ratio in the resulting ferrite $\mathrm{Ni}_{0.3} \mathrm{Zn}_{0.7} \mathrm{Fe}_{2} \mathrm{O}_{4}$. Subsequently, $0.03 \%$ vol. of acetic acid (Sigma Aldrich, 99.7\%) was added to the prepared solution. The prepared solutions were electrospun by Nanospider TM NS Lab (ELMARCO) equipped by needle-less electrospinning technology. The applied voltage was $80 \mathrm{kV}$, the spinning distance between spinning and collector electrodes was in a range of $130-140 \mathrm{~mm}$. The electrospinning was performed at ambient temperature with a relative humidity of $50 \%$. After electrospinning, the electrospun composite nanofiber mats were dried at $90^{\circ} \mathrm{C}$ for 15 minutes. The pure single phase spinel ferrite $\left(\mathrm{Ni}_{0.3} \mathrm{Zn}_{0.7} \mathrm{Fe}_{2} \mathrm{O}_{4}\right)$ was obtained after annealing of precursor fibers in air at atmospheric pressure, at $800^{\circ} \mathrm{C}$ for 4 hour with a heating rate of $10^{\circ} \mathrm{C} / \mathrm{min}$.

\section{Composites preparation}

The base ferromagnetic FeSi powder ( $97 \mathrm{wt} \%$ of $\mathrm{Fe}$ and $3 \mathrm{wt} \%$ of $\mathrm{Si}$ ) was commercially obtained from Höganäs Corporation [16]. The three different types of composites were prepared:

i) A $-0.1 \mathrm{~g}$ of ferrite fibers were mixed with $3 \mathrm{ml}$ of Glycerol and $20 \mathrm{~g}$ of FeSi powder was subsequently added to this suspension. The prepared mixture was dried in the oven at $200^{\circ} \mathrm{C}$ and compacted at $600 \mathrm{MPa}$.

ii) $\mathrm{B}-0.1 \mathrm{~g}$ of ferrite fibers were mixed with 1drop of Glycerol, 20g of FeSi particles was mixed with the prepared mixture and immediately compacted at $600 \mathrm{MPa}$ without drying.

iii) $\mathrm{C}-0.1 \mathrm{~g}$ of ferrite powder was mixed with small amount of Ethanol and mixed with $20 \mathrm{~g}$ of FeSi particles. The mixture was drying at $60^{\circ} \mathrm{C}$ after completely evaporation of ethanol. The prepared coated powder was compacted at $600 \mathrm{MPa}$.

The coated powder was compacted in cylindrical die without any further additives. Density of powder and bulk composite was measured by He-pycnometer AccuPyc II 1340 and calculated from the sample dimensions, respectively. The prism-shaped samples (dimensions $5 \times 4 \times 20 \mathrm{~mm}(\mathrm{w} \times \mathrm{h} \times \mathrm{l})$ ) were used to evaluate elastic properties represented by Young modulus (E) - Impulse excitation method and software Buzz-o-Sonic and transverse rupture strength (TRS) measured by 3 point bending test using universal testing machine Tiratest 2100. The cylindrical shaped samples (dimensions of $10 \times 3 \mathrm{~mm}(\mathrm{~d} \times \mathrm{h})$ ) were used to measure the hardness tests using TUKKON 1102 hardness tester. The electric resistivity was measured by 4 point probe method using Mitsubishi Loresta AXMCP-T370.

\section{Experimental method for properties evaluation}

The surface morphology and microstructure of precursors and final ferrite nanofiber was studied by scanning electron microscopy (SEM/FIB, ZEISS AURIGA COMPACT). The thermal decomposition of the samples was analyzed by differential scanning calorimetry (DSC) supplemented with thermogravimetric analysis (JUPITER STA 449-F1 NETZSCH). The phase and crystallinity of calcined membranes were investigated by a X-ray diffraction analysis (XRD, PhilipsX' PertPro, $\mathrm{CuK} \alpha$ radiation). The substructure of $\mathrm{Ni}_{0.3} \mathrm{Zn}_{0.7} \mathrm{Fe}_{2} \mathrm{O}_{4}$ nanofibers was observed by transmission electron microscopy (TEM, JEOL 2100F). 


\section{RESULTS AND DISCUSSION}

\section{Thermal and XRD analysis of precursor fibers}

TG/DSC analysis was performed for the precursors PAN/Ni, Zn, Fe (nitrates) fibers (Fig.1). The data shows that the larges weight mass loss was recorded at the temperature $151.5^{\circ} \mathrm{C}$, which was invoked by a rapid decomposition of PVA and auto-self combustion process accompanied by evolution of volatile-by products. The rapid evolution of monomers is also reflected in exothermic reaction in DSC curve. A more gradual release and weight loss takes place in the temperature region $500-1000^{\circ} \mathrm{C}$ responsible for burningout of nitrate metal salts. The trasformation of final spinel structutre of $\mathrm{Ni}_{0.3} \mathrm{Zn}_{0.7} \mathrm{Fe}_{2} \mathrm{O}_{4}$ was evident at the temperatures $607^{\circ} \mathrm{C}, 702^{\circ} \mathrm{C}$ and $940^{\circ} \mathrm{C}$. The sintering temperature of $\mathrm{NiZnFe}_{2} \mathrm{O}_{4}$ fibers was set up according to this observation.

Figure 2 shows XRD pattern of the ferrite product derived after thermal decomposition of precursor at $800^{\circ} \mathrm{C}$ for four hours in air. The characteristic diffraction peaks were identified as (111), (311), (222), (400), (422), (511), (440), (533) and represent the main crystal planes in the pure spinel.

The different morphology between precursor fibers and fibers after thermal treatment is observed in Fig.3a,b,c,d. The precursor fibers (Fig.3a) consisting of PVA and metals nitrate salts exhibited cylindrical shape, uniform, continuous length with smooth surface. The diameters of precursors fibers were between $0.5-1.5 \mu \mathrm{m}$. On the other hand, the final ferrite fibers (Fig.3b) with thickness only about 100-250nm exhibited ribbon-shape morphology, which can be attributed to the collapse of hollow fibers, earlier reported in the work of Fong et.al [17]. The TEM and HRTEM image confirmed that the final ferrite fibers had polycrystalline character arranged with $20 \mathrm{~nm}$ cubic monograins (Fig.3c). The EDX analysis of ferrite fibers after thermal treatment confirmed the presence of $\mathrm{Ni}, \mathrm{Zn}, \mathrm{Fe}$ without any additional impurities (Fig.3d).

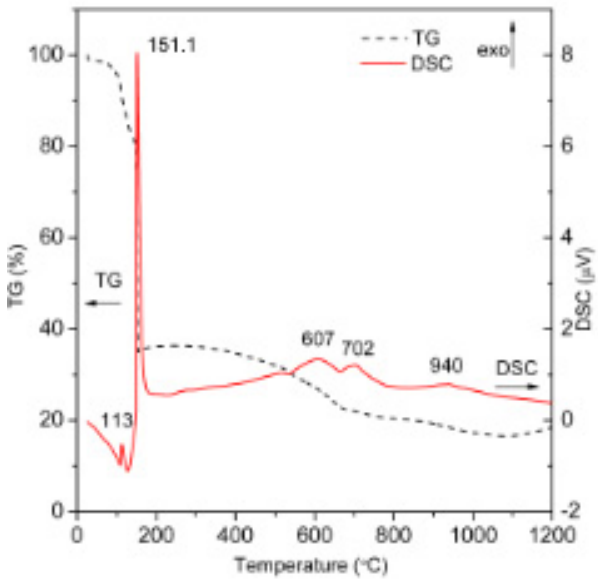

Fig.1. TG/DSC analysis of PAN/Ni,Zn,Fe nitrates.

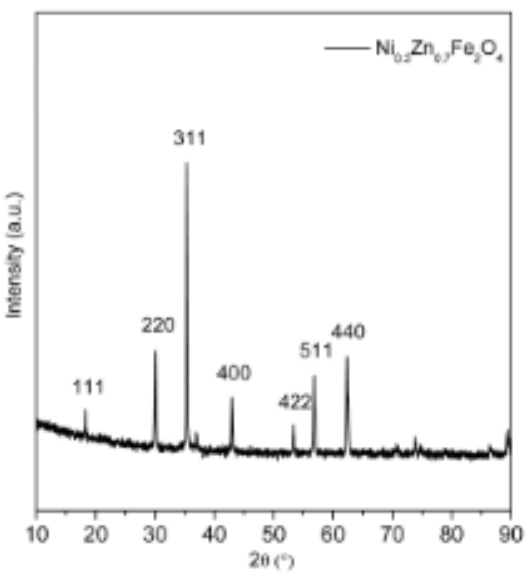

Fig.2. XRD of ferrite $\mathrm{Ni}_{0.3} \mathrm{Zn}_{0.7} \mathrm{Fe}_{2} \mathrm{O}_{4}$ fibers. 


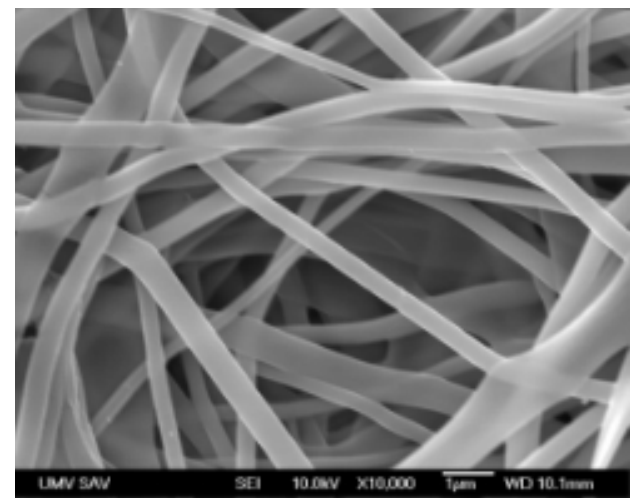

a)

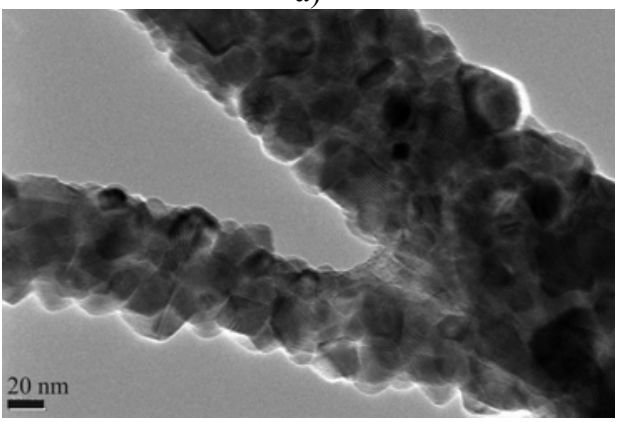

c)

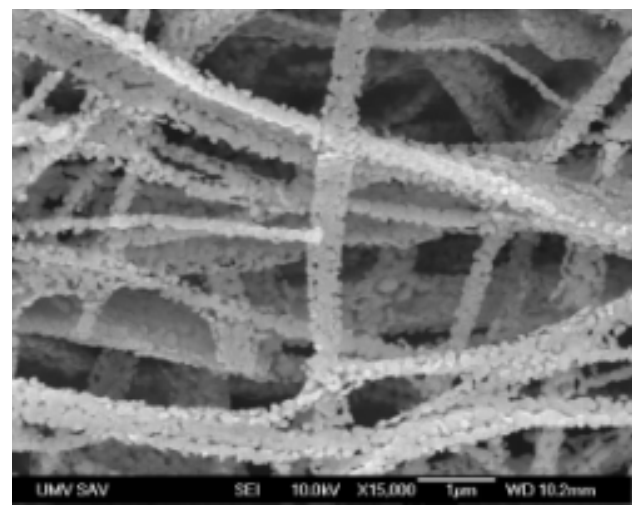

b)

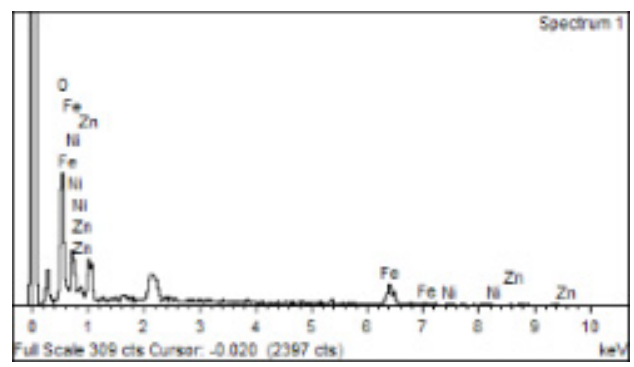

d)

Fig.3. The morphological analysis of $\mathrm{Ni}_{0.3} \mathrm{Zn}_{0.7} \mathrm{Fe}_{2} \mathrm{O}_{4}$ fibers a) precursor PAN/Ni,Zn,Fe nitrates, b) ferrite fibers after thermal treatment, c) TEM analysis of polycrystalline character, d) EDX analysis.

\section{Composite characterization}

The first evaluated system - composite type A was created by combination of FeSi ferromagnetic particles as a core and ferrite fibers despised in glycerol as a coating. The homogenization of $\mathrm{FeSi}$ particle with suspension was finalized by evaporation and solidification of coating in the oven at $200^{\circ} \mathrm{C}$. The SEM images of this system are visualized on Fig.4. The prepared ferrite coating as the secondary phase is evident like adhesive and compact coating grouped a more FeSi particles to the large agglomerates (Fig. $4 \mathrm{a})$. The incorporation of $\mathrm{Ni}_{0.3} \mathrm{Zn}_{0.7} \mathrm{Fe}_{2} \mathrm{O}_{4}$ fibers in the coating is visualized on the detail of the surface (Fig. 4b) and the presence of ferrites was confirmed by EDX analysis. On the Fig. $4 \mathrm{c}$ is presented the morphology of the final bulk material $\mathrm{FeSi} / \mathrm{Ni}_{0.3} \mathrm{Zn}_{0.7} \mathrm{Fe}_{2} \mathrm{O}_{4}$ after compaction and final sintering process. The prepared composite coating is visible as the very fine shell on the FeSi surface which was partially slough after breaking of the sample during transverse rupture strength test. The examination of fracture surface of prism shape sample confirmed propagation of expansive crack localized close to the surface. It is tempting to conjecture that large amount of glycerol contained in the sample underwent to the degradation during thermal treatment what was responsible for this undesirable effect. According these experiences, the system B was composed of lower amount of glycerol (only for safe manipulation with fumed fibers) and mixed with spinel fibers for a coating preparation. FeSi powder as a core added again. The prepared core-shell particles (Fig.5a,b) 
were immediately compacted without any previous drying. The continuous and uniform coating was observed on the surface of FeSi particles after compaction process (Fig. 5c). The differences between fraction surfaces of the samples with larger (Fig. 4c) and smaller (Fig. 5c) amount of glycerol is evident. More refined cracks were observed in the sample with a lower content of glycerol what lead to the higher shape and dimensional stability of the sample. The last evaluated system - $\mathrm{C}$ was prepared by mixing of ferrite fibers with small amount of ethanol and FeSi powder, without any addition of glycerol. The excess of ethanol was evaporated from the mixture at $60{ }^{\circ} \mathrm{C}$. Figure $6 \mathrm{a}$ has shown the uneven distribution of ferrite fibers on the FeSi surface which has tendency to agglomerate to one place (see the white arrows). The morphology of the $\mathrm{FeSi} / \mathrm{Ni}_{0.3} \mathrm{Zn}_{0.7} \mathrm{Fe}_{2} \mathrm{O}_{4}$ sample prepared through mixing of ethanol is depicted in Fig.6b. However the interesting observation was found in the interparticle spaces after compaction process as evidenced SEM images at a higher magnification (Fig.6c). It is clear that FeSi substrate obviously support the different composition and morphology of designed layers. No visible deformation, pores and cracks was observed on the SEM image after fracture of sample (Fig. 6d).

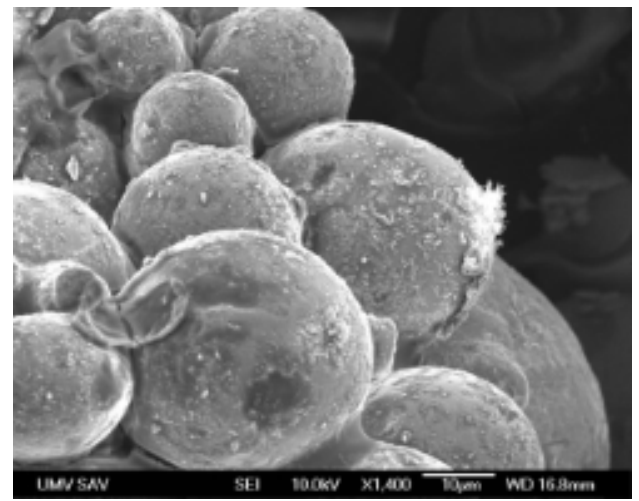

a)

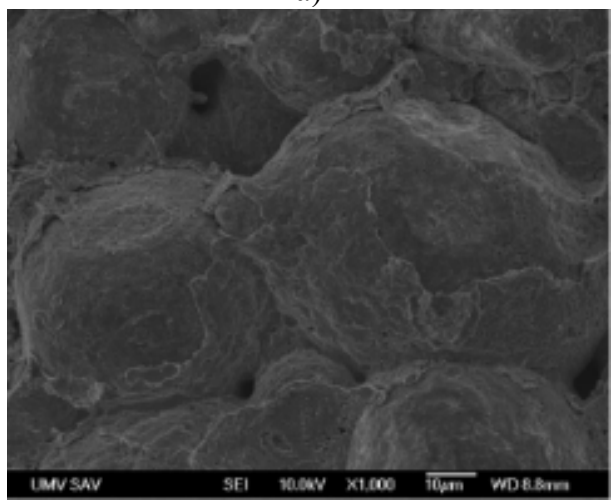

c)

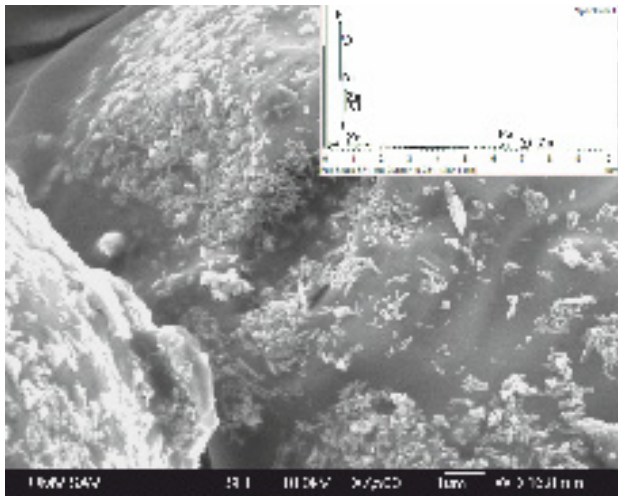

b)

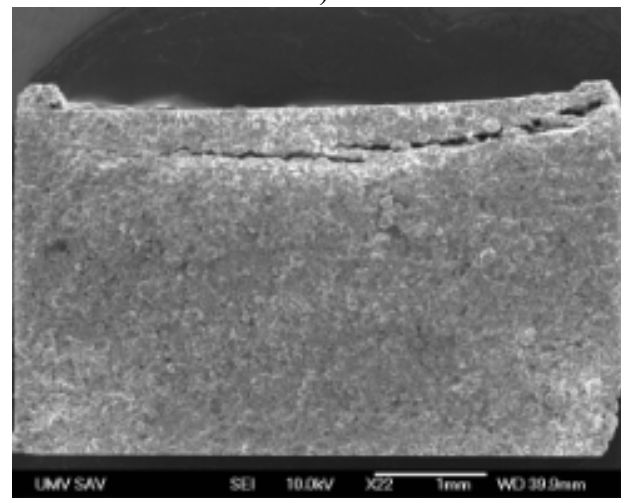

d)

Fig.4. SEM image of FeSi/ $\mathrm{Ni}_{0.3} \mathrm{Zn}_{0.7} \mathrm{Fe}_{2} \mathrm{O}_{4}$ composite sample type A: a) coated powder by ferrite fibers and glycerol, b) detail of coating, c) microstructure after compaction, d) macrostructure of fractured surface. 


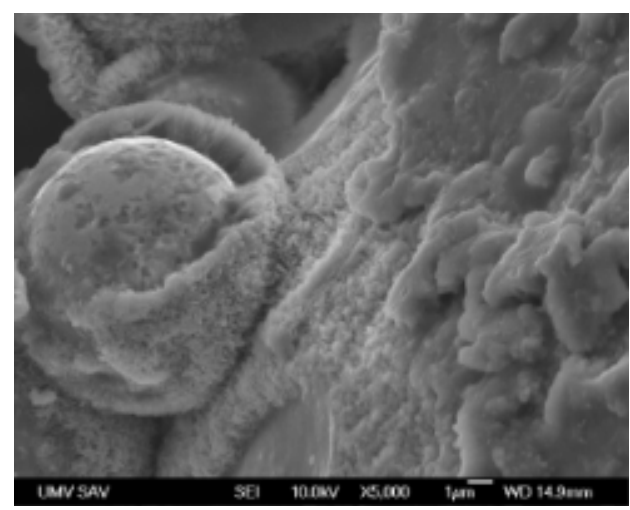

a)

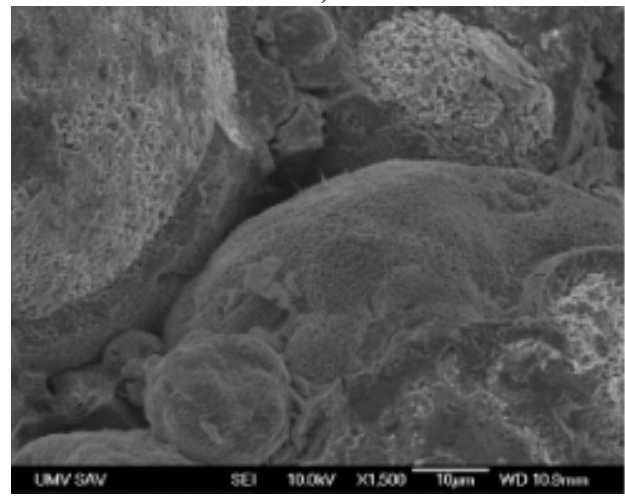

c)

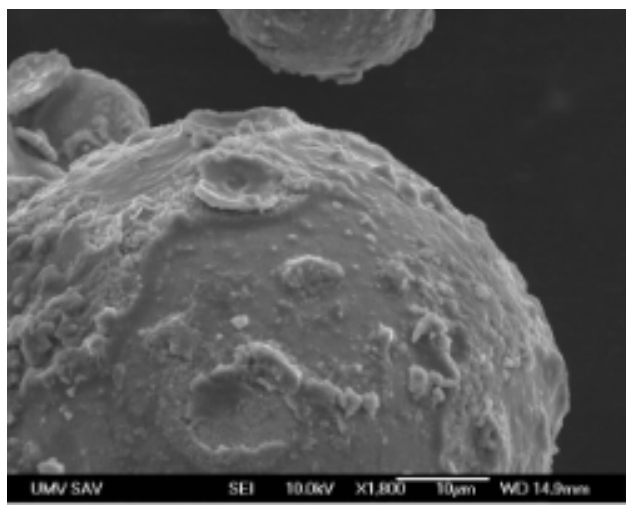

b)

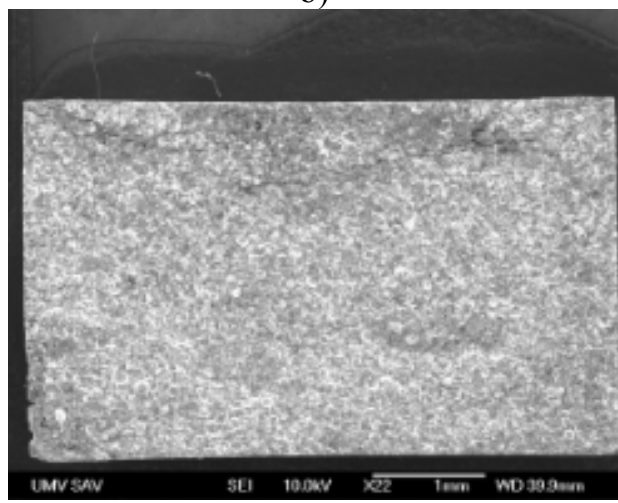

d)

Fig.5. SEM image of FeSi/ $\mathrm{Ni}_{0.3} \mathrm{Zn}_{0.7} \mathrm{Fe}_{2} \mathrm{O}_{4}$ composite sample type $\mathrm{B}$ : a) coated powder by ferrite fibers and glycerol, b) detail of coating, c) microstructure after compaction, d) macrostructure of fractured surface.

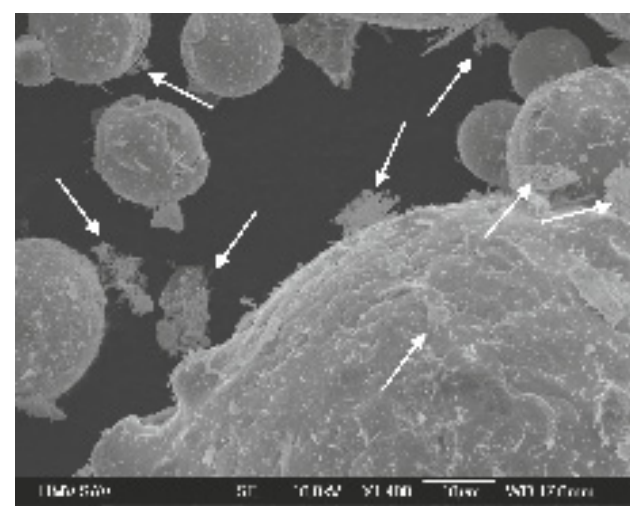

a)

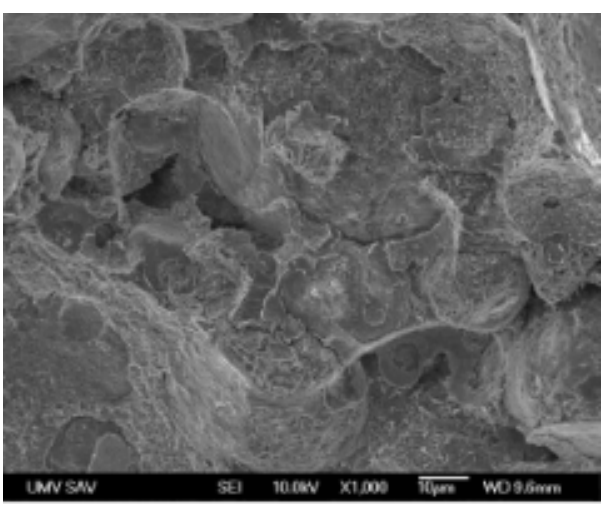

b) 


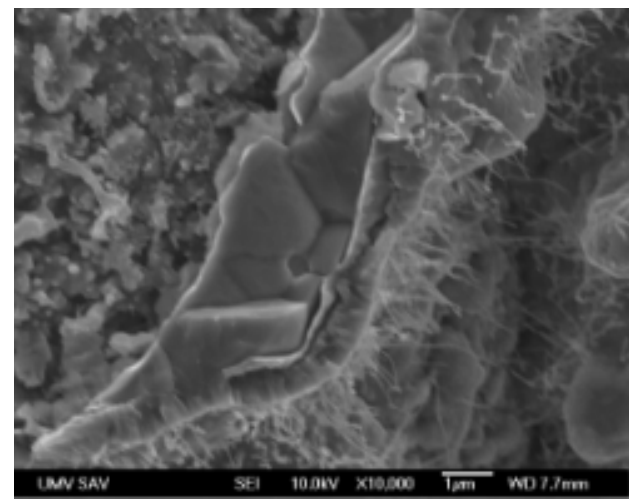

c)

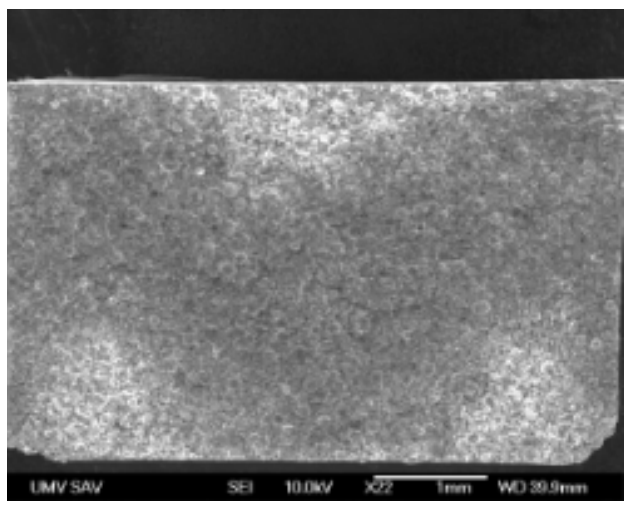

d)

Fig.6. SEM image of FeSi/ $\mathrm{Ni}_{0.3} \mathrm{Zn}_{0.7} \mathrm{Fe}_{2} \mathrm{O}_{4}$ composite sample type $\mathrm{C}$ : a) coated powder by ferrite fibers and ethanol, b) microstructure after compaction, c) detail of interface, d)macrostructure of fractured surface.

\section{Properties of $\mathrm{FeSi} / \mathrm{Ni}_{0.3} \mathrm{Zn}_{0.7} \mathrm{Fe}_{2} \mathrm{O}_{4}$}

Table 1 shows that the mechanical properties and electric resistivity of the final composite $\mathrm{FeSi} / \mathrm{Ni}_{0.3} \mathrm{Zn}_{0.7} \mathrm{Fe}_{2} \mathrm{O}_{4}$ which were significantly affected by the distribution, thickness and amount of the secondary ferrite phase. The measured and calculated values of the bulk density indicate insignificant porosity in the prepared composite samples. For a comparison, the density of the pure sintered FeSi powder is around $7.15{\mathrm{~g} . \mathrm{cm}^{-3}}^{\text {[18] }}$ and density of $\mathrm{FeSi} /$ phenol formaldehyde resin composite reached $6.41 \mathrm{~g} . \mathrm{cm}^{-3}$ [19] what is comparable with composite material of type A. It is of technological importance that the measured values of mechanical hardness, transverse rupture strength and Young modulus for the $\mathrm{FeSi} / \mathrm{Ni}_{0.3} \mathrm{Zn}_{0.7} \mathrm{Fe}_{2} \mathrm{O}_{4}$ composite are quite superior with respect to the values of FeSi/phenol-formaldehyde resin $(\mathrm{TRS}=97 \mathrm{MPa}$ and $\mathrm{E}=34 \mathrm{GPa})$. The most homogeneous distribution of the insulating coating manifests composite type $\mathrm{C}$ with sufficiently high specific electric resistivity, which is almost two orders of magnitude greater than the specific electric resistivity of composite type A. The very low electric resistivity and high coercivity was observed for sample B what can be attributed damage of the coating and penetration contacts between the particles.

Tab.1. Basic properties of composite materials base on FeSi powder and $\mathrm{Ni}_{0.3} \mathrm{Zn}_{0.7} \mathrm{Fe}_{2} \mathrm{O}_{4}$ ferrite fibers.

\begin{tabular}{|c|c|c|c|c|c|}
\hline Sample & $\begin{array}{c}\text { Density } \\
{\left[{\left.\mathrm{g} . \mathrm{cm}^{-3}\right]}^{-3}\right.}\end{array}$ & $\begin{array}{c}\mathrm{E} \\
{[\mathrm{GPa}]}\end{array}$ & $\begin{array}{c}\text { TRS } \\
{[\mathrm{MPa}]}\end{array}$ & $\begin{array}{c}\text { Coercivity } \\
{\left[\mathrm{A} \cdot \mathrm{m}^{-1}\right]}\end{array}$ & $\begin{array}{c}\text { Resistivity } \\
{[\Omega . \mathrm{cm}]}\end{array}$ \\
\hline A & 6.17 & 115 & 70 & 720 & 15 \\
\hline B & 6.14 & 117 & 98 & 1130 & 0.0003 \\
\hline C & 6.45 & 134 & 90 & 850 & 700 \\
\hline
\end{tabular}

\section{CONCLUSION}

The novel composite material was designed from the spherical FeSi particles and the soft magnetic ferrite fibers $\mathrm{Ni}_{0.3} \mathrm{Zn}_{0.7} \mathrm{Fe}_{2} \mathrm{O}_{4}$ with the inverse spinel structure. The aforementioned $\mathrm{Ni}_{0.3} \mathrm{Zn}_{0.7} \mathrm{Fe}_{2} \mathrm{O}_{4}$ ferrite fibers were produced by the needle-less electrospinnig techniques from PAN-metal nitrate solutions. The precursor fibers were 
calcined at $800^{\circ} \mathrm{C}$ according to the TG/DSC measurement The three types of coated composites powder were prepared with regard to the value of glycerol or ethanol in the mixture. The composite powder coated by the suspension composed of glycerol/ethanol ferrite fibers were subsequently processed by PM technologies to the green compacts. The inverse spinel structure of the prepared $\mathrm{Ni}_{0.3} \mathrm{Zn}_{0.7} \mathrm{Fe}_{2} \mathrm{O}_{4}$ ferrite fibers was confirmed by XRD analysis. SEM images have enabled us to identify the uniformity and homogeneity of the prepared coating before and after compaction.

It has been found that the fine ferrite fibers structure provides a very convenient secondary phase because allow to prepare the composites with the tight arrangement of spherical FeSi particles onto dense body without any significant porosity. It turns out that the mechanical properties of the final $\mathrm{FeSi} / \mathrm{Ni}_{0.3} \mathrm{Zn}_{0.7} \mathrm{Fe}_{2} \mathrm{O}_{4}$ composite are quite superior with respect to that ones of the polymeric analogous composites, in which the organic binder (mostly phenol-formaldehyde resin) is used as the insulating coating. However the most homogeneous distribution of the insulating coating is reflected in a rather high specific electric resistivity of the composite sample prepared with ethanol, which indicates perspective application of this SMC material at medium and high frequencies due to a substantial reduction of relevant eddy current losses. According to this, the investigation of basic magnetic characteristics and their optimization represents a challenging task for our future work.

\section{Acknowledgement}

This work was supported Scientific Grant Agency of the Ministry of Education of Slovak Republic and the Slovak Academy of Sciences, project VEGA 2/0185/15 and Slovak Research and Development Agency under the contract APVV 15-0115.

\section{References}

[1] Shokrollahi, H., Janghorban, K.: Journal of Materials Processing Technology, vol. 189, 2007, nos. 1-3, p. 1

[2] Sunday, KJ., Taheri, ML.: Metal Powder Report, vol. 00, 2016

[3] Slusarek, B., Jankowski, B., Sokalski, K., Szczygłowski, J.: J. Alloys Compd., vol. 581, 2013, p. 699

[4] Streckova, M., Bures, R. et all. : Chin. J. Chem. Eng., accepted manuscript

[5] Neamţu, BV., Geoffroy, O., Chicinaş, I., Isnard, O.: Mat. Sci. Eng. B, vol. 177, 2012, p. 661

[6] Wu, S., Sun, A., et all: J. Magn. Magn. Mater., vol. 324, 2012, p. 3899

[7] Kronmuller, H.: Handbook of Magn. and Adv. Magn. Mat. Wiley, 2007 ISBN: 0470022175

[8] Sudakar, C., Subbanna, GN., Kutty, TRN.: J Magnetism Magn Mater, vol. 268, 2004, p. 75

[9] Young-Wan Ju, Jae-Hyun Park, Hong-Ryun Jung, Sung-June Cho, Wan-Jin Lee: Materials Science and Engineering B, vol. 147, 2008, p. 7

[10] Montana Sangmanee, Santi Maensiri: Appl Phys A, vol. 97, 2009, p. 167

[11] John Berchmans, L., Kalai Selvan, R. et all: J Magnetism Magn Mater, vol. 279, 2004, p.103

[12] Goldberg, HA.: High magnetic permeability composites containing fibres with ferrite fill.US States Patent 4725490, 1988

[13] Fang, J., Niu, HT., Lin,T., Wang, XG.: Chin. Sci. Bull., vol. 53, 2008, p. 2265

[14] Wu, H., Pan, W., Lin, D., Li, D.: J. Adv. Ceram., vol. 1, 2012, p. 1

[15] Jirsak, O., Sysel, P., et all: J. Nanomater., vol. 1, 2010, p. 6 
[16] Högänes datasheet, www.haganas.com

[17] Fong, H., Liu, WD., et all: Polym., vol. 43, 2002, p. 775

[18] http://www.pramiz.com/softm.html

[19] Streckova, M., Füzer, J., Kobera, L. et all: Materials Chemistry and Physics, vol. 147, 2014, p. 649 